\title{
Functional parameters of the cutting process of the cutting tool with multilayer coatings after pulsed laser treatment
}

\author{
Sergei Sizov, ${ }^{1, *}$, Vladimir Tabakov ${ }^{2}$, and Aleksey Chikhranov ${ }^{2}$ \\ ${ }^{1}$ Joint-Stock Company Ulyanovsk Design Bureau of Instrumentation, Ulyanovsk, Russian Federation \\ ${ }^{2}$ Federal State Budgetary Educational Institution of Higher Education Ulyanovsk Technical State \\ University, Ulyanovsk, Russian Federation
}

\begin{abstract}
The paper presents the results of functional parameters of the cutting process using the multilayer coated cutting tool based on nitrides of titanium, zirconium, niobium and aluminum - TiN-TiZrN-TiZrAlN, TiNTiZrN-TiZrNbAlN before and after the impulse laser processing. It was demonstrated that the impulse laser processing shortens the overall contact length between chips and the front surface, decreases the chips shorting coefficient, cutting force components and the heat flow capacity at the front surface. The shortening of the overall contact length gives some boost to the rate of heat flows along the front and rear surfaces. This fact decreases contact temperatures in comparison with the instrument without the pulsed laser treatment. It was demonstrated that the shortening of the overall contact length between chips and the front surface after the pulsed laser treatment adjusts temperature filed isotherms and stress isobars in the tool cutting wedge to the rear surface and the cutting edge.
\end{abstract}

\section{Introduction}

The working capacity improvement of the cutting tool in the modern machinery production can be achieved based on the application of hard wear-resistant coatings [1 - 5]. Whereby the greater effect will be achieved, if contact surfaces of the cutting tool are covered with multilayer coatings $[3,6,7]$. To improve the application efficiency of multilayer coatings it is possible to additionally apply the pulsed laser treatment (PLT) [7-10]. When designing multilayer coatings it is important to evaluate the impact of PLT on changing of the cutting process by the cutting tool. This research is to study functional parameters of the cutting process using the multilayer coated cutting tool after PLT.

\section{Methodology of experiment}

Multilayer coatings were applied at carbide blades MK8 using the machine «Bulat-6». Contact characteristics of the cutting process were determined according to the working

\footnotetext{
*Corresponding author: serg.sizov24@yandex.ru
} 
procedure [11], the thermal state was evaluated according to the working procedure [12]. The temperature and stress distribution in the cutting wedge of the tool was calculated using the software application package ANSYS. To evaluate coating properties experimental researches of the thermal state of the tool cutting wedge when turning pieces made of $38 \mathrm{XГН} \mathrm{steel} \mathrm{were} \mathrm{carried} \mathrm{out.} \mathrm{Cutting} \mathrm{modes:} 1$ mode: $V=130 \mathrm{~m} / \mathrm{min}, S=0,3$ $\mathrm{mm} / \mathrm{turn}, t=0,75 \mathrm{~mm} ; 2$ mode: $V=170 \mathrm{~m} / \mathrm{min}, S=0,15 \mathrm{~mm} / \mathrm{turn}, t=0,5 \mathrm{~mm}$.

\section{Research results and discussion}

The multilayer coatings architecture was selected taking into account their formation principle suggested in researches $[3,13]$. According to this principle in case of continuous turning the coating should provide favorable conditions for the contact interaction of the processed and tooling material at the front surface which can reduce the equivalent stress in the cutting wedge of the tool and improve its shape stability. Simultaneously to keep the process of the cracks formation and their intensity mechanical properties of the coating and the level of proper compressing residual stress shall further the formation of high normal compressing stress in them during the cutting process. As illustrated in researches $[5,13]$ multiple-element coatings (for example three-element) based on the modified titanium nitride meet these requirements to the fullest extent. Apart from the abovementioned requirements the coating shall provide the high-strength adhesion with the tooling base which is stronger in one-element coating in comparison with multiple-element ones.

Having regard to the above said and taking into consideration the functional purpose of layers of the multiple-element coating we examined coatings TiN, TiN-TiZrN-TiZrAlN, TiN-TiZrN-TiZrNbAlN before and after the pulsed laser treatment. Coatings TiN-TiZrNTiZrAlN, TiN-TiZrN-TiZrNbAlN were applied using titanium, zirconium, titanium alloys, aluminum and niobium cathodes. The thickness of coatings in all cases was 6 micron.

To calculate the thermal state the overall contact length between chips and the front surface $C_{\gamma}$, the chips shorting coefficient $K_{L}$ and cutting force components $P_{x}, P_{y}, \underline{P}_{z}$ were observed. Results are included in the Table 1.

Table 1. The influence of the pulsed laser treatment on contact characteristics of the cutting process when turning pieces made of $38 \mathrm{X} \Gamma \mathrm{H}$ steel

\begin{tabular}{|l|c|c|c|c|c|}
\hline \multicolumn{1}{|c|}{ Coating } & $C_{\gamma}, \mathrm{mm}$ & $K_{L}$ & $P_{x}, \mathrm{~N}$ & $P_{y}, \mathrm{~N}$ & $P_{z}, \mathrm{~N}$ \\
\hline TiN & $0.65 / 0.47$ & $1.92 / 1.76$ & $95 / 68$ & $263 / 102$ & $491 / 198$ \\
\hline TiN+ PLT & $0.58 / 0.33$ & $1.76 / 1.55$ & $87 / 61$ & $243 / 87$ & $472 / 183$ \\
\hline TiN-TiZrN-TiZrAlN & $0.71 / 0.55$ & $1.98 / 1.88$ & $101 / 81$ & $272 / 119$ & $508 / 205$ \\
\hline TiN-TiZrN-TiZrAlN+ PLT & $0.63 / 0.38$ & $1.80 / 1.70$ & $93 / 77$ & $258 / 100$ & $492 / 183$ \\
\hline TiN-TiZrN-TiZrNbAlN & $0.69 / 0.51$ & $2.09 / 1.90$ & $112 / 90$ & $289 / 115$ & $517 / 210$ \\
\hline TiN-TiZrN-TiZrNbAlN+ PLT & $0.61 / 0.39$ & $1.85 / 1.78$ & $101 / 82$ & $277 / 102$ & $496 / 194$ \\
\hline Nind
\end{tabular}

Note: values of the mode 1 are the numerator and values of the mode 2 are the nominator

It is found that when cutting under lower cutting speeds and greater feed and the cutting depth, PLT of abrasion-resistant coatings when turning pieces made of $38 \mathrm{XГН} \mathrm{steel}$ shortens the contact length between chips and the front surface $C_{\gamma}$ by $10.7-11.6 \%$, decreases the chips shorting coefficient $K_{L}$ by $8.3-11.6 \%$ and cutting force components $P_{x}, P_{y}, P_{z}$ by 2.6-8.9\% depending on the composition and the structure of coatings. The shortening of the overall contact length $C_{\gamma}$ after PLT increases average normal and tangential stresses at the front surface of the cutting tool by $11.1-11.8 \%$ and by $5.7-7.7 \%$ depending on the cutting mode. When cutting at higher cutting speeds and lesser feeds and cutting depths the same changing regularities of contact characteristics of the cutting process when using PLT are observed. 
To measure contact temperatures at the front and the rear surface of the tool we used the analytical solution of A.N. Reznikov. Findings of the thermal state of the tool cutting wedge are included in the Table 2.

Table 2. The influence of the pulsed laser treatment on the thermal state of the cutting tool

\begin{tabular}{|l|c|c|c|c|c|c|}
\hline \multicolumn{1}{|c|}{ Coating } & $Q_{f}, \mathrm{~W}$ & $Q_{r}, \mathrm{~W}$ & $q_{f}, \mathrm{MW} / \mathrm{m}^{2}$ & $q_{r}, \mathrm{MW} / \mathrm{m}^{2}$ & $T_{f m},{ }^{\circ} \mathrm{C}$ & $T_{r m},{ }^{\circ} \mathrm{C}$ \\
\hline TiN & $16.7 / 10.7$ & $-2.2 /-1.9$ & $23.8 / 32.2$ & $-40.9 /-53.5$ & $887 / 821$ & $436 / 414$ \\
\hline TiN+ PLT & $15.8 / 10.2$ & $-2.3 /-2.3$ & $25.7 / 43.3$ & $-43.5 /-64.4$ & $875 / 814$ & $407 / 376$ \\
\hline TiN-TiZrN-TiZrAlN & $17.3 / 12.2$ & $-2.2 /-2.2$ & $23.0 / 31.2$ & $-41.6 /-60.8$ & $913 / 885$ & $455 / 425$ \\
\hline $\begin{array}{l}\text { TiN-TiZrN-TiZrAlN+ } \\
\text { PLT }\end{array}$ & $16.6 / 11.2$ & $-2.3 /-2.4$ & $24.8 / 41.5$ & $-43.9 /-68.2$ & $901 / 879$ & $421 / 380$ \\
\hline TiN-TiZrN-TiZrNbAIN & $18.3 / 12.5$ & $-2.4 /-2.3$ & $25.0 / 34.5$ & $-45.3 /-64.6$ & $971 / 925$ & $473 / 436$ \\
\hline $\begin{array}{l}\text { TiN-TiZrN-TiZrNbAlN+ } \\
\text { PLT }\end{array}$ & $17.6 / 11.6$ & $-2.6 /-2.4$ & $27.3 / 41.9$ & $-49.4 /-68.8$ & $962 / 911$ & $426 / 405$ \\
\hline
\end{tabular}

Note: values of the mode 1 are the numerator and values of the mode 2 are the nominator

After finishing the analysis of data included in the Table 2 we can reach the conclusion that the application of PLT reduces the heat flow capacity at the front surface $Q_{f}$ by 3.8 $5.4 \%$ and insignificantly increases at the rear surface $Q_{r}$ by $4.5-8.3 \%$. The shortening of the contact length $C_{\gamma}$ after PLT slightly increases the rate of heat flows along the front surface $q_{f}$ and the rear surface $q_{r}$ by $9.2-12.7 \%$ and by $6.4-9.1 \%$ in comparison with the tool without PLT. Changing of the heat flows capacity at the front surface $Q_{f}$ and the rear surface $Q_{r}$ and their rates $q_{f}$ and $q_{r}$ leads to changing of contact temperatures. The application of ILP leads to the decrease of contact temperatures at the front surface $T_{f m}$ and the rear surface $T_{r m}$ of the cutting tool by $0.9-1.4 \%$ and $6.7-9.9 \%$ in comparison with the tool without PLT. The application of coatings TiN decreases contact temperatures at the front surface $T_{f m}$ and the rear surface $T_{r m}$. The application of multi-element coatings in comparison with the coating TiN increases them.

PLT of the cutting tool with coatings has an impact on temperature fields in its cutting wedge. As can be seen in Figure 1 the shortening of the overall contact length between chips and the front surface after PLT of the cutting tool with the coating TiN leads to the adjustment of temperature filed isotherms to the rear surface and the decrease of the temperature flow along the front surface leads to their adjustment to the front surface.
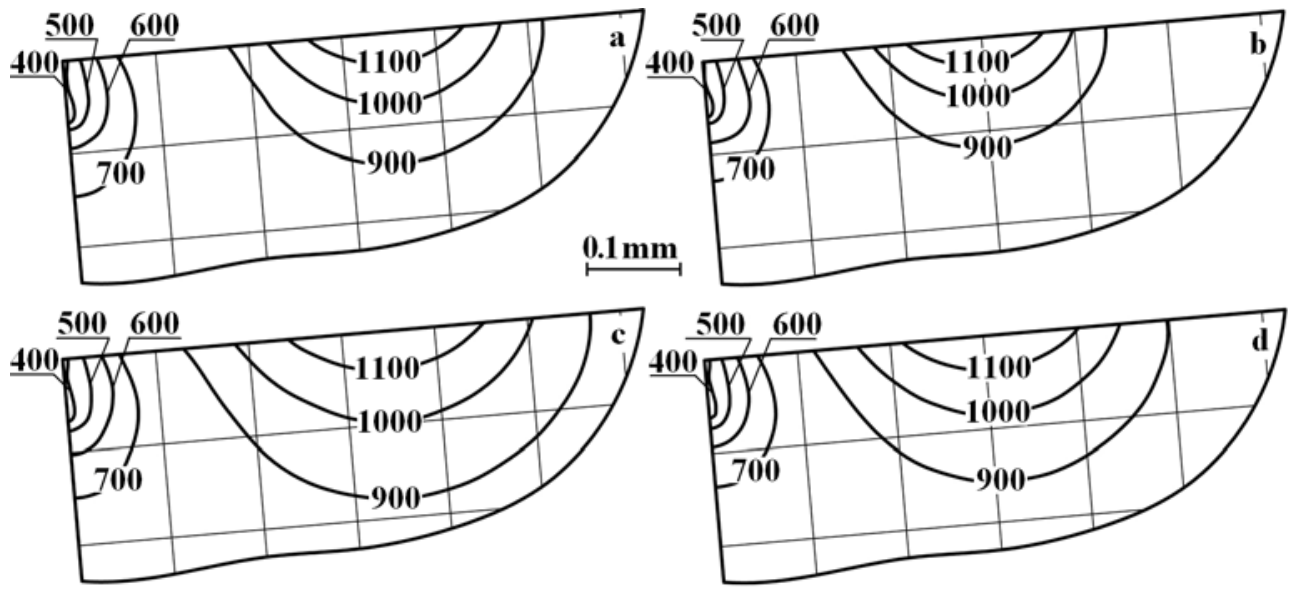

Fig. 1. The stress distribution $\sigma_{x}(\mathrm{MPa})$ in the cutting wedge of the carbide tool with coatings: a - TiN; b - TiN+PLT; c - TiN-TiZrN-TiZrNbAlN; d - TiN-TiZrN-TiZrNbAlN+PLT $(V=130$ $\mathrm{m} / \mathrm{min}, S=0,3 \mathrm{~mm} / \mathrm{turn}, t=0,75 \mathrm{~mm})$ 
The extension of the overall contact length between chips and the front surface typical for the multi-element coating TiN-TiZrN-TiZrNbAlN in comparison with the coating TiN apart from the increase in capacity of the thermal source leads to the adjustment of temperature filed isotherms in the cutting wedge of the tool to the rear surface, cutting edges of the tool and in depth of the tooling base.

The stressed state of the tool cutting wedge was estimated under normal and tangential stresses at the front surface and stresses $\sigma_{x}$ at the tool cutting wedge along the front surface.

It is found that the pulsed laser treatment leads to some increase in normal stresses. Results of stress calculations at the cutting wedge showed that stress isobars $\sigma_{x}$ as the result of the overall contact length shortening between chips and the front surface in case of using the pulsed laser treatment are adjusted to the rear surface of the tool and their occurrence depth is decreased (Figure 2).
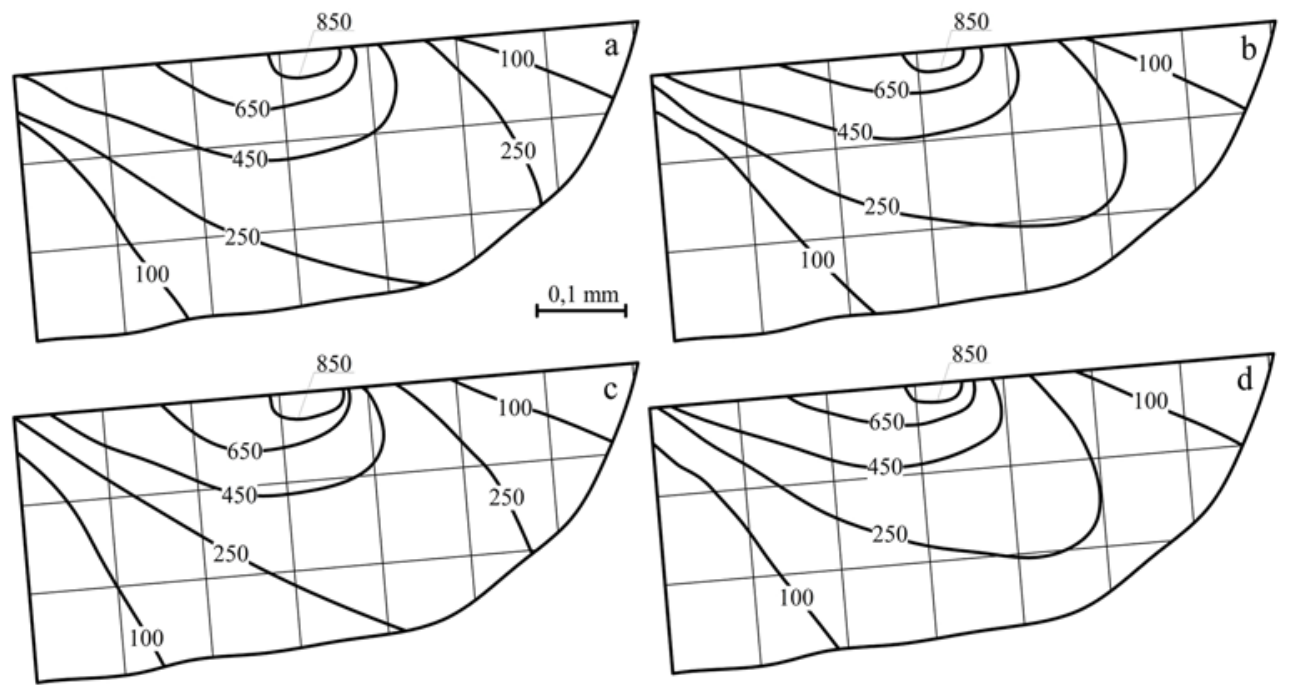

Fig. 2. The stress distribution $\sigma_{x}(\mathrm{MPa})$ in the cutting wedge of the carbide tool with coatings: $\mathrm{a}-\mathrm{TiN} ; \mathrm{b}-\mathrm{TiN}+\mathrm{PLT}$; $\mathrm{c}-\mathrm{TiN}-\mathrm{TiZrN}-\mathrm{TiZrNbAIN} ; \mathrm{d}-\mathrm{TiN}-\mathrm{TiZrN}-\mathrm{TiZrNbAIN}+\mathrm{PLT}(V=130$ $\mathrm{m} / \mathrm{min}, S=0,3 \mathrm{~mm} /$ turn, $t=0,75 \mathrm{~mm}$ )

\section{Conclusion}

It is found that the application of the pulsed laser treatment changes functional parameters of the cutting process using the cutting tool with coatings. The impulse laser processing leads to the shortening of the overall contact length between chips and the front surface, the chips shortening coefficient, cutting force components and contact temperatures. The shortening of the contact length between chips and the front surface is the reason for some increase in normal and tangential stresses at the front surface and the adjustment of temperature isotherms and stress isobars at the cutting wedge to the rear surface. The analysis of research results of cutting contact characteristics and the thermal state is the basis to conclude that changing of functional parameters of the cutting process using the cutting tool with coatings after the pulsed laser treatment shall lead to the improvement of its efficiency. 


\section{References}

1. M.A. Volosova, V.D. Gurin, Influence of vacuum-plasma nitride coatings on contact processes and a mechanism of wear of working surfaces of high-speed steel cutting tool at interrupted cutting, Journal of Friction and Wear, v. 34(3), pp. 183-189 (2013)

2. M.E. Maximov, Durable Coatings and Their Application to Improve the Performance of Cutters, (Iznosostoykiye pokrytiya $\mathrm{i}$ ikh primeneniye $\mathrm{v}$ povyshenii ekspluatatsionnykh kharakteristik rezhushchego instrumenta), Bulletin of the Moscow State Technical University MAMI, v. 4(22), pp. 27-34 (2014)

3. A.S. Vereshchaka, A.A. Vereshchaka, A.I. Bulycheva, Multi-layer Nanodispersive Coatings for Cutters, (Mnogosloynye nanodispersnye pokrytiya dlya rezhushchego instrumenta), Strengthening Technologies and Coatings, (Uprochnyayushchiye tekhnologii i pokrytiya), v. 5, pp. 33-39 (2014)

4. S.N. Grigoriev, A.A. Vereschaka, A.S. Vereschaka, A.A. Kutin, Cutting tools made of layered composite ceramics with nano-scale multilayered coatings, Procedia CIRP, v. 1, pp. 318-323 (2012)

5. V.P. Tabakov, A.V. Chikhranov, Selecting the composition of wear-resistant coatings, Russian Engineering Research, v. 38(2), pp. 105-109 (2018)

6. V.P. Tabakov, A.S. Vereschaка, Development of technological means for formation of multilayer composite coatings, providing increased wear resistance of carbide tools, for different machining condition, Key Engineering Materials, v. 581, pp. 55-61 (2014)

7. S.N. Wlasov, R.R. Bagautdinov, Simulations of the effects of high energy multi-layered instrumental composition (Modelirovanie vozdeystviya vysokikh energiy na mnogosloynuyu instrumentalnuyu kompozitsiyu), Youth scientific bulletin (Molodezhnyy nauchnyy vestnik), v. 12(25), pp. 154-158 (2017)

8. D. Neves, A.E. Diniz, M.S.F. Lima, Microstructural analyses and wear behavior of the cemented carbide tools after laser surface treatment and PVD coating, Appl. Surf. Sci., v. 282, pp. 680-688 (2013)

9. D. Neves, A.E. Diniz, M.S.F. Lima, Efficiency of the laser texturing on the adhesion of the coated twist drills, Journal of Materials Processing Technology, v. 179, pp. 139145 (2006)

10. J.M. Arroyo, A.E. Diniz, M.S.F. Lima. Wear performance of laser precoating treated cemented carbide milling tools // Wear-v., v. 268, pp. 1329-1336 (2010)

11. A.D. Makarov, Optimization of cutting processes (Optimizatsiya protsessov rezaniya) (Moscow: Mashinostroenie, 1976)

12. A.N. Reznikov Thermophysics of processes of mechanical processing of metals (Teplofizika protsessov mekhanicheskoy obrabotki metallov) (Moscow: Mashinostroenie, 1981)

13. V.P. Tabakov, S.N. Grigoryev, A.S. Vereshchaka, Principles of Generating and Applying Durable Cutter Coatings, (Printsipy formirovaniya i tekhnologii naneseniya iznosostoykikh pokryty rezhushchego instrumenta), Ulyanovsk State Technical University (2012) 